\title{
A novel application of nano eggshell/titanium dioxide composite on occluding dentine tubules: an in vitro study
}

\author{
Stanley Chibuzor ONWUBU(a) \\ Phumlane Selby MDLULI(b) (iD \\ Shenuka SINGH(c) iD \\ Tshepo TLAPANA(d) \\ (a) Durban University of Technology - DUT, \\ Dental Sciences, Durban, South Africa. \\ (b)Durban University of Technology - DUT, \\ Chemistry, Durban, South Africa. \\ (c) University of KwaZulu-Natal - UKZN, \\ Dentistry, Durban, South Africa. \\ (d) Durban University of Technology - DUT \\ Marketing, Durban, South Africa.
}

Declaration of Interests: The authors certify that they have no commercial or associative interest that represents a conflict of interest in connection with the manuscript.

Corresponding Author:

Stanley Chibuzor Onwubu

E-mail:21445599@dut4life.ac.za

htrps://doi.org/10.1590/1807-3107bor-2019.vol33.0016

Submitted: September 4, 2018

Accepted for publication: January 10, 2019

Last revision: January 17, 2019
Abstract: To synthesize Nano eggshell-titanium-dioxide (EB@TiO2) biocomposite and to evaluate its effectiveness in occluding opened dentine tubules. EB@TiO2 was synthesized and characterized using X-ray diffraction (XRD), and Transmission Electron Microscope (TEM). Sixteen simulated bovine dentine discs were prepared and randomly assigned into four groups according to the following treatment $(n=4)$ : Group 1: No treatment; Group 2: eggshell powder; Group 3: EB@TiO2; Group 4: Sensodyne. These were then agitated in a solution of $1 \mathrm{~g}$ powder and $40 \mathrm{~mL}$ water for 3 hours. Thereafter, each dentine discs from the respective groups were post-treated for $5 \mathrm{~min}$ with $2 \mathrm{wt} \%$ citric acid to test their acid resistant characteristics. Scanning Electron Microscope (SEM) was used to observe the effectiveness of occluded dentine preand post-treatment. The cytotoxicity of the synthesized EB@TiO2 was tested using NIH 3T3 assay. ANOVA was used to evaluate the mean values of the occluded area ratio and the data of MTS assay. This was followed by a multi-comparison test with Bonferroni correction $(\alpha=.05)$. The XRD confirmed that EB@TiO2 was successfully modified through ball-milling. The TEM revealed the presence of both spherical and irregular particle shape powders. The SEM result showed that EB@TiO2 could effectively occlude open dentine tubules. Equally, the result demonstrated that EB@TiO2 exhibited the highest acid resistant stability post-treatment. NIH 3T3 assay identified that EB@TiO2 had little effect on the NIH 3T3 cell line even at the highest concentration of $100 \mu \mathrm{g} / \mathrm{ml}$. This study suggests that the application of EB@TiO2 effectively occluded dentine tubules and the occlusion showed a high acid resistant stability.

Keywords: Dentin; Dentin Sensitivity; Dentin Desensitizing Agents; Tooth Remineralization.

\section{Introduction}

Dentine Hypersensitivity [DH] is a common occurrence and under extreme conditions when dentine tubules is exposed to the oral cavity patients will experience a short, sharp pain. ${ }^{1}$ From a public health perspective, $\mathrm{DH}$ is a significant oral health concern 
affecting more than $43 \%$ of adult's population worldwide. ${ }^{2}$ As a consequence, $\mathrm{DH}$ if left untreated will negatively affect the quality of life for dental patients'. In particular, and as Schiff et al. ${ }^{3}$ points out, DH sufferers tend to modify their habits by eliminating certain foods and drinks from their regular diets and they become non-complaint with specific at-home care recommendations such as tooth brushing. Consequently, caries formation, gingival inflammation and periodontal problems are likely to increase. Yang et al. ${ }^{4}$ have therefore advised using an occlusion agents to physically block exposed dentine tubules.

Over the last decades, the oral care industry have witnessed proliferation of different occlusion materials for treating DH. Among these materials, the use of potassium oxalates, ${ }^{5}$ sodium fluoride, ${ }^{6}$ strontium salt, ${ }^{2}$ amorphous calcium phosphate containing casein phosphopeptide, ${ }^{7}$ calcium glycerophosphate, ${ }^{8}$ and calcium carbonates (mainly as abrasive agents) ${ }^{9}$ have gain significant interest as an occlusion materials. Although the aforementioned occlusion materials have been reported to provide some relief to patients, the dentine tubules occluded by some of these materials are reported to be superficial with limited infiltration depth-which could be readily re-exposed in an acidic environment. ${ }^{10}$ Thus, short-living the treatment effects and subsequently resulting to $\mathrm{DH}$ relapse. ${ }^{11}$ Given the limited drawbacks, developing a desirable biomaterials for $\mathrm{DH}$ becomes highly critical to not only efficiently occlude the exposed dentine tubules, but also remain effective in acidic environment.

Of interest, eggshells are currently being investigated for their remineralization capabilities. ${ }^{12}$ More recently, Haghgoo et al. ${ }^{13}$ reported that eggshell has a rich bioavailable calcium content, which favours the remineralizing of caries lesions. Cutler ${ }^{14}$ suggested that nanosized titanium dioxide and dental abrasive agents can be used together in occluding open dentine tubules. Other scholar have indicated that nanosized titanium dioxide can improve the acid resistant properties of calcium carbonates. ${ }^{15}$ Given the desirable properties of titanium dioxide $\left(\mathrm{TiO}_{2}\right)$ and the remineralization potentials of eggshells (EB), a new $\mathrm{EB} @ \mathrm{TiO}_{2}$ bio composite will be highly important for treating $\mathrm{DH}$.
Despite the enormous potential of eggshell-titanium dioxide bio composite, there is limited evidence in its use for occluding dentine tubules. The study aimed to synthesize Nano eggshell-titanium-dioxide (EB@ $\mathrm{TiO}_{2}$ ) bio composite and evaluate its effectiveness in occluding opened dentine tubules. The hypothesis tested was that $\mathrm{EB} @ \mathrm{TiO}_{2}$ will effectively occlude open dentine tubules and the occlusion show more acidic resistant.

\section{Methodology}

\section{Preparation of Eggshell-Titanium dioxide composite (EB@TiO $)$}

Modification of eggshell with titanium dioxide was achieved in two steps. In the first step, eggshells were ball-milled by placing $30 \mathrm{~g}$ of the eggshell in a $500 \mathrm{ml}$ stainless jar (inner diameter of $100 \mathrm{~mm}$ ), together with 10 stainless steel balls of $10 \mathrm{~mm}$ diameter and dry-milled in a planetary ball mill (Retsch ${ }^{\circledR} \mathrm{PM} \mathrm{100)}$ ) at $400 \mathrm{rpm}$ for $20 \mathrm{~min}$. The collected powder was sieved to a particle size of $\leq 25 \mu \mathrm{m}$ using a mechanical sieving shaker (Retsch AS 200, Germany). The eggshell powder and titanium dioxide mixing ratio was optimized following the procedure reported by Lin et al. ${ }^{16} 20 \mathrm{~g}$ of the fine eggshell powder obtained in step 1 were modified by adding $5 \mathrm{~g}$ of anatase titanium dioxide $(\leq 15 \mu \mathrm{m})$. The mixture was subsequently ball-milled for $200 \mathrm{~min}$ to obtain eggshell-titanium dioxide bio composite.

\section{Characterization of EB@TiO}

\section{X-Ray Diffraction Analysis}

The X-ray diffraction (XRD) analysis was performed to observe the possible changes in crystallinity between the eggshell powder, titanium dioxide, and $\mathrm{EB} @ \mathrm{TiO}_{2}$. The XRD patterns were recorded using a diffractometer (PANalytical-Empyrean instrument; Co radiation $1.54056 \mathrm{~A}^{\circ}$ ) and analysed between $0-90^{\circ}$ ( 2 theta). The voltage, current and pass time used were $40 \mathrm{Kv}, 40 \mathrm{~mA}$ and 1s, respectively.

\section{Microscopic analysis}

A Transmission Electron Microscope (TEM) was used to observe the particle size, shape and 
distribution of $\mathrm{EB} @ \mathrm{TiO}_{2}$. Very small quantities of $\mathrm{EB} @ \mathrm{TiO}_{2}$ were dispersed in $10 \mathrm{ml}$ ethanol and sonicated at $10 \mathrm{kv}$ for $10 \mathrm{~min}$. Subsequently, thin cross-sections of cryo-microtomed specimens were prepared using a Leica microtome (South Africa) and placed on carbon copper grids. Analysis was conducted using a transmission electron microscope (TEM-Philips CM 120 model) at 120 kV.

\section{Specimen preparation and acidic challenge}

Sixteen freshly extracted bovine-enamel anterior teeth were obtained from a slaughter house, South Africa. The collected teeth were subsequently cleaned and disinfected in $10 \%$ chloroxylenol solution. Dentin discs measuring $5 \mathrm{~mm} \times 5 \mathrm{~mm} \times 1 \mathrm{~mm}$ was prepared by sectioning perpendicular to the long axis of the teeth below the enamel-dentinal junction using a low-speed diamond saw under water cooling conditions. Subsequently, the prepared dentin disc was wet grounded with silicon carbide polishing papers (600-1,000 grits) for 60 seconds. Before simulating the sensitive tooth model, the discs were mounted in a resin (AMT composite, South Africa). Silicone mold (Silicone rubber mold; Agar scientific) was used to make a mounting base. A fast setting resin (F160: AMT composite) was mixed in a disposable plastic cup in a 1:1 ratio and poured into the mold. After approximately 2 minutes. The embedded resin was removed from the silicone mold. Thereafter, dentine tubules was opened by soaking the specimens in $1 \mathrm{wt}$. \% citric acid solution for $30 \mathrm{~min}$. The specimens were randomly assigned into four groups ( $\mathrm{n}=4)$, namely:

a. Group 1: No treatment group.

b. Group 2: Eggshell powder treated group.

c. Group 3: EB@ $\mathrm{TiO}_{2}$ treated group, and

d. Group 4: Sensodyne treated group.

The specimens were agitated in a beaker containing $1 \mathrm{~g}$ of the synthesized EB@ $\mathrm{TiO}_{2}$ and $40 \mathrm{~mL}$ deionized water for 3 hours. Similar procedure were followed for eggshell powder and Sensodyne paste. The specimens were subsequently rinse and blot tried. More so, and as a proxy measure, a representative of each sample group were selected to determine the acid resistant characteristics of the treated specimen. This were subsequently exposed to $2 \mathrm{wt}$. \% citric acid solution ( $\mathrm{pH} 2$ ) for $5 \mathrm{~min}$. After exposure, the specimens were rinsed with deionized water and blot tried.

\section{Scanning electron microscope evaluation of the occluded specimen}

Scanning electron microscope (Field Emission-Carl Zeiss) operating at controlled atmospheric conditions at $20 \mathrm{kV}$ was used to evaluate the occluded dentine preand post-acidic exposure. Prior to SEM observation, the surface was coated with a thin, electric conductive gold film to prevent build-up of electrostatic charge. In addition, the ratios of occluded tubules was further computed using ImageJ software (National Institute of Health USA, http://imagej.nih.gov./ij). This was calculated by dividing the area of occluded tubules by the total tubules area using $\times 3000$ magnification images $(n=4)$.

\section{Cytotoxicity assay}

Eggshell powder and $\mathrm{EB} @ \mathrm{TiO}_{2}$ samples were dispersed in Dimethyl Sulfoxide (DMSO), before the administration to the cell line. An MTS assay (3-(4,5-dimethylthiazol-2-yl)-5-(3-carboxymethoxyphenyl)-2-(4-sulfophenyl)-2H-tetrazolium) was used to evaluate change in cell viability. The samples were tested across 2 plates in duplicate $(n=6)$ and the average value reported. NIH 3 T3 cells were grown using normal tissue culture techniques. The cells $(1 \times 105$ cells $/ \mathrm{ml})$ were incubated in 96 well plates at $37^{\circ} \mathrm{C}$ overnight, with the subsequent addition of the supplied compounds, in concentrations of $(100 \mu \mathrm{g} / \mathrm{ml}$, $50.0 \mu \mathrm{g} / \mathrm{ml}, 25.0 \mu \mathrm{g} / \mathrm{ml}, 12.5 \mu \mathrm{g} / \mathrm{ml}, 6.25 \mu \mathrm{g} / \mathrm{ml}$, and $3.13 \mu \mathrm{g} / \mathrm{ml})$. The cells were left to incubate for 4 days. Thereafter, MTS $(5 \mu \mathrm{l})$ was added to the cells. The absorbance values were measured at $490 \mathrm{~nm}$ after $1 \mathrm{~h}, 2 \mathrm{~h}$ and 4 hour incubation periods, averaged and the viability curves drawn up.

\section{Statistical analysis}

The mean values of the occluded area ratio in SEM study and the $\%$ viability data of MTS assay were evaluated with 1-way analysis of variance (ANOVA) using statistical software (IBM SPSS Statistics v24; 
- A novel application of nano eggshell/titanium dioxide composite on occluding dentine tubules: an in vitro study

IBM Corp). This was followed by a multi-comparison test with Bonferroni correction $(\alpha=.05)$.

\section{Results}

\section{Characterization}

The XRD analysis of eggshell powder titanium dioxide, and the synthesized $\mathrm{EB} @ \mathrm{TiO}_{2}$ are presented in Figure 1. For Figure 1A, the characteristic peak marked around $34.5^{\circ}(2 \theta)$ indicates the presence of thermodynamically stable calcite crystalline structure, which is similar to calcium carbonate. ${ }^{17}$ The $\mathrm{EB} @ \mathrm{TiO}_{2}$ diffraction peak with values lying at $2 \theta=29.5^{\circ}$ corresponds to anatase phase and is confirmed with International Centre for Diffraction Data (ICDD Ref: 98-009-6946). Consistent with Tao et al. ${ }^{15}$, the shape, intensity, and location of the $\mathrm{EB} @ \mathrm{TiO}_{2}$ peaks corresponding to the anatase

A

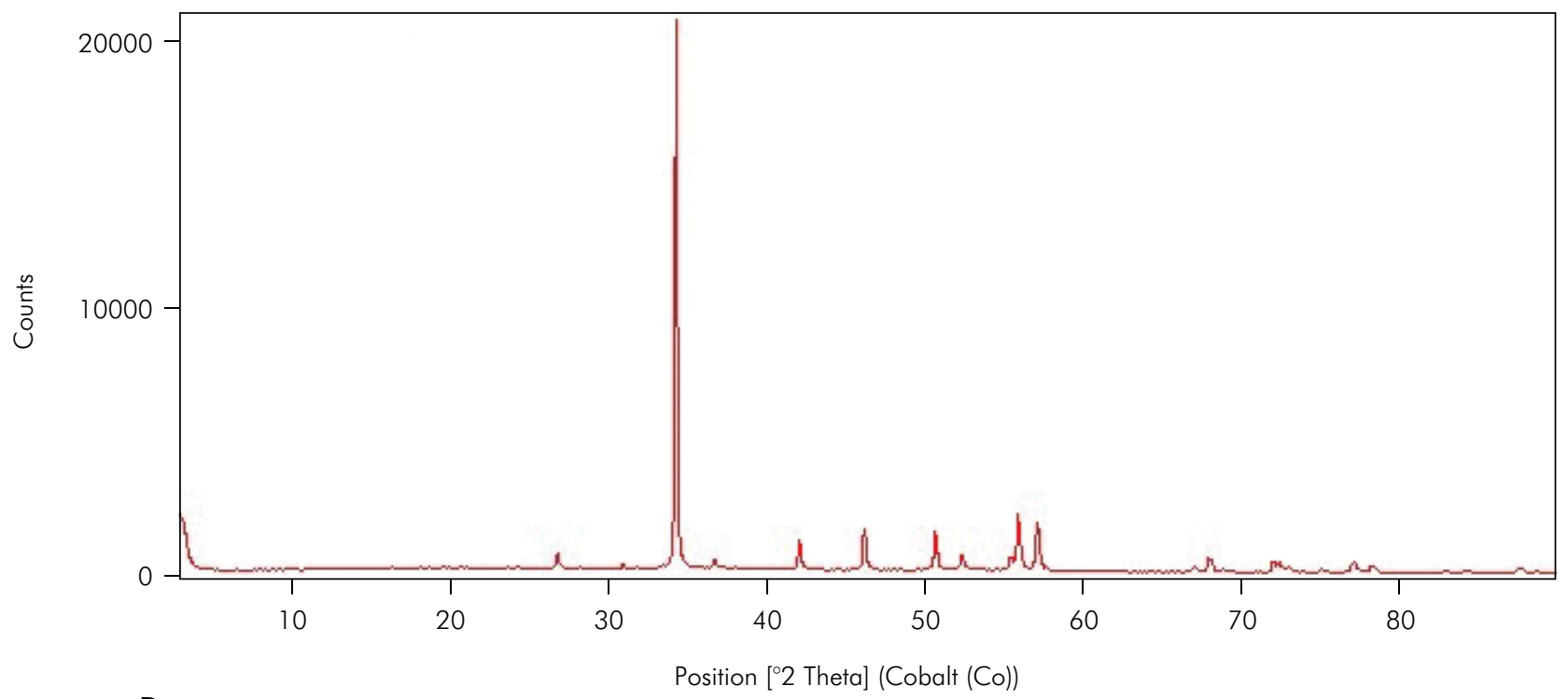

B

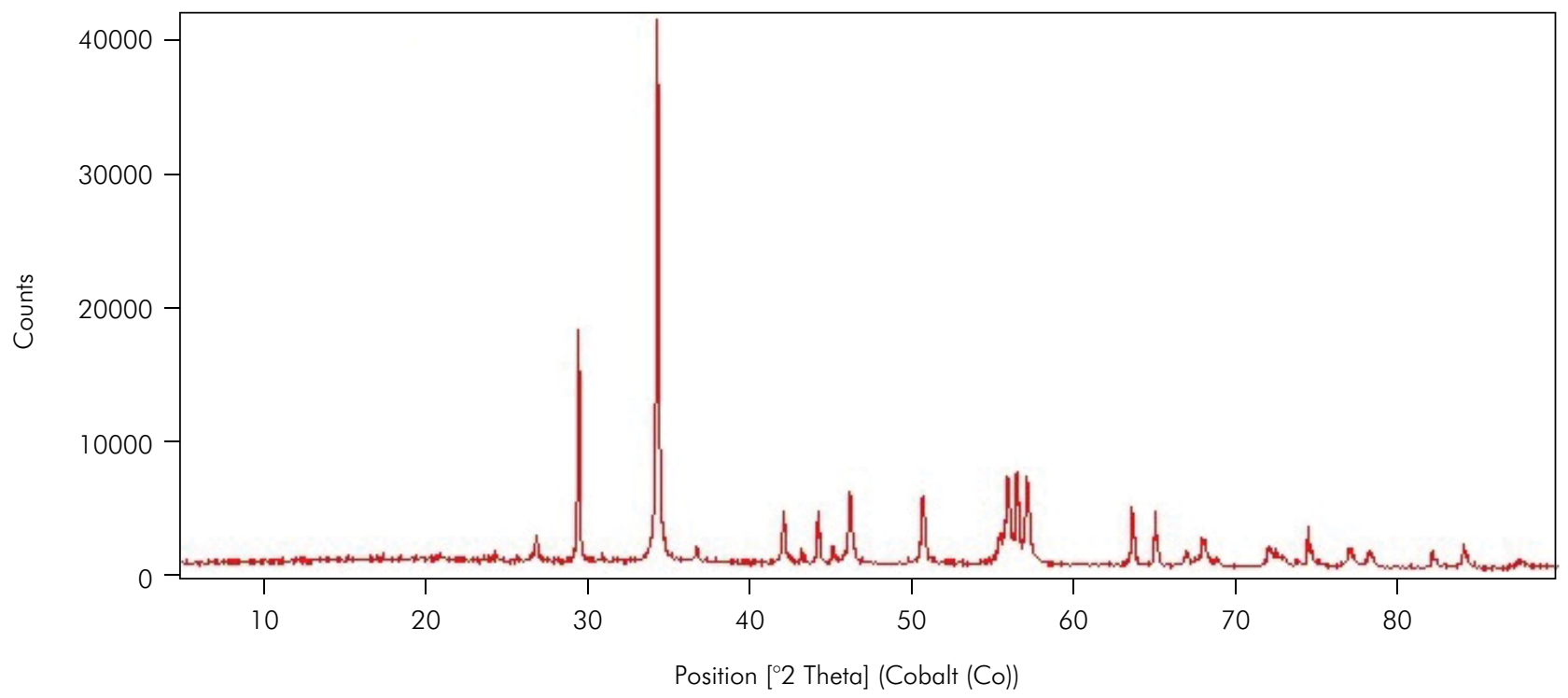

Figure 1. XRD pattern of (A) eggshell powder; (B) $\mathrm{EB} @ \mathrm{TiO}_{2}$. 

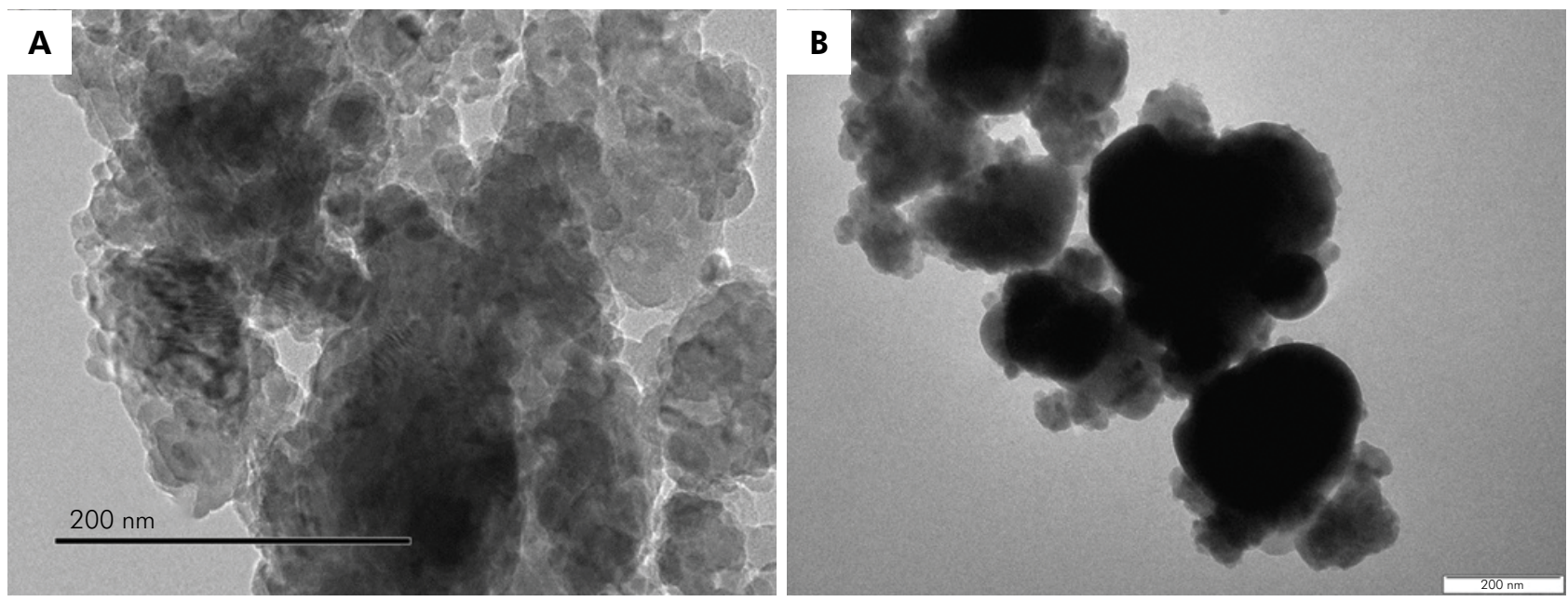

Figure 2. TEM images: (A) eggshell powder; (B) EB@ $\mathrm{TiO}_{2}$.

suggests the deposition of $\mathrm{TiO}_{2}$ on the surface of the $\mathrm{CaCO}_{3}$.

The morphology, shape and particle size of eggshell powder and $\mathrm{EB} @ \mathrm{TiO}_{2}$ were studied using TEM. According to the TEM image in Figure 2 A, an irregular particle shape were notice in the eggshell. In contrast, and as seen in Figure $2 B$, the presence and irregular particle shapes coexisted with a spherical shape particles. The presence of the irregular shaped particles is attributed to the calcite shape of the eggshell powder whilst the spherical shaped particles typified the presence of $\mathrm{TiO}_{2}$.

\section{Cytotoxicity testing}

The viability of NIH $3 \mathrm{~T} 3$ cell lines exposed to different concentrations of eggshell powder and $\mathrm{EB} @ \mathrm{TiO}_{2}$ are shown in Figure 3. The samples were tested against NIH 3T3 mouse fibroblasts cell lines. No significant difference was determined among the various groups $(p>0.05)$. Equally, there were no significant differences in all pairwise comparisons amongst the different concentrations ( $p>0.05$ ).

\section{Observation of the occluded dentine tubules}

The 1-way ANOVA, mean, standard deviation, and standard error results are given in Table 1. Notably, the mean ratio of occluded tubules values for the specimens treated with eggshell powder $\mathrm{EB} @ \mathrm{TiO}_{2}$, and Sensodyne were statistically different $(\mathrm{p}<.001)$.

The specimens treated with EB@TiO2 showed highest mean occluded areas $\left(83.25 \pm 12.47 \mu \mathrm{m}^{2}\right)$, while the specimen group treated with Sensodyne covered the lowest open tubules $\left(25.00 \pm 8.04 \mu \mathrm{m}^{2}\right)$. The results of the post hoc comparison test (Table 2) suggests that area of tubules occluded by EB@ $\mathrm{TiO}_{2}$ group were significantly higher than those for the eggshell powder group $(p<.001)$ and the Sensodyne group $(p<.05)$. Equally, statistical differences were found in the occluded tubules for the groups treated with eggshell powder and Sensodyne $(p<.05)$.

The SEM micrograph of the occluded dentine tubules pre-and post-treatment in different sample groups are displayed in Figure 4. In group 1 (A1-B1), it was observed that the dentine surfaces were free of smear layer and all the dentine tubules were open after agitation in $1 \mathrm{wt}$. \% citric acid for $30 \mathrm{~min}$. In group 2 (A2-B2), the dentine tubules were partially blocked with some visibly open tubules. In group 3 (A3-B3), the dentine tubules were completely blocked by the particles of $\mathrm{EB} @ \mathrm{TiO}_{2}$. In group 4 (A4-B4), most of the dentine tubules still remain open after treatment with Sensodyne. In addition, the SEM image (C2-C4) revealed differences in the treated dentine specimen post-treatment in $2 \mathrm{wt} \%$ citric acid. For example, and in contrast to the images 


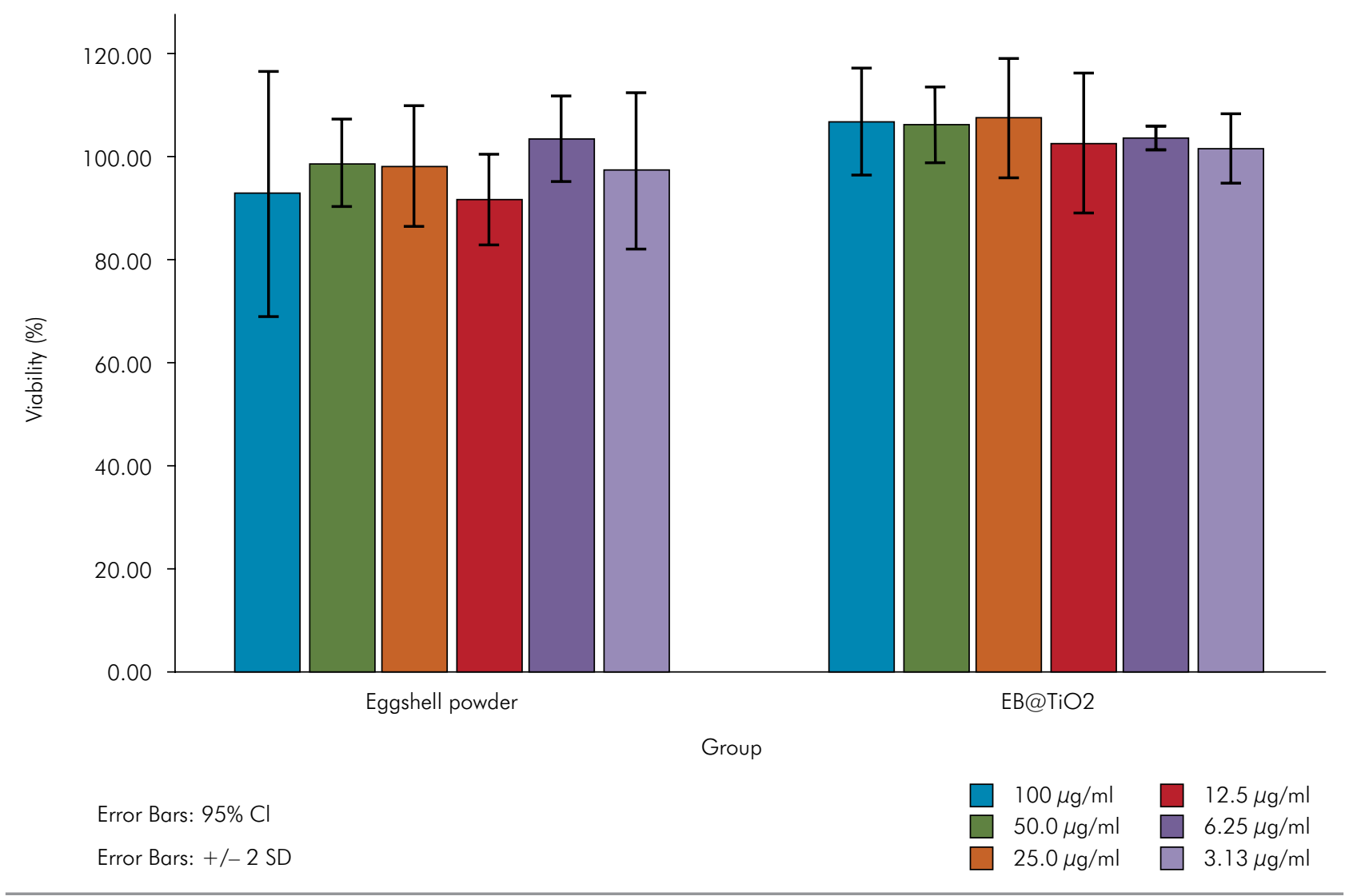

Figure 3. Percentage cell viability.

Table 1. ANOVA test for the occluded dentine tubules after treatment.

\begin{tabular}{lcccc}
\hline Variable & $\mathrm{n}$ & Mean & Std. Deviation & $\mathrm{p}$-value \\
\hline No treatment & 4 & - & - & \\
Eggshell powder & 4 & 56.5 & 6.03 & \\
${\mathrm{~EB} @ \mathrm{TiO}_{2}}$ & 4 & 83.25 & 12.47 & $0.000^{*}$ \\
Sensodyne & 4 & 25.0 & 8.04 & \\
\hline
\end{tabular}

Table 2. Bonferroni multiple comparison test.

\begin{tabular}{lcc}
\hline \multirow{2}{*}{ Polishing material } & \multicolumn{2}{c}{ Bonferroni } \\
\cline { 2 - 3 } & $p$-value & Sig. \\
\hline EB@TiO2 Eggshell power & 0.008 & Significant \\
EB@TiO2 Sensodyne & 0.000 & Significant \\
Eggshell powder Sensodyne & 0.003 & Significant \\
\hline
\end{tabular}

for the specimens treated with eggshell powder (C2) and Sensodyne (C4), the images of the specimen treated $\mathrm{EB} @ \mathrm{TiO}_{2}(\mathrm{C} 3)$ suggest more resistance to acidic challenge.

\section{Discussion}

It is well documented in literature that tooth erosion attributed to high consumption of citric acid containing soft drinks is increasingly seen as a public health concern, thus contributing to $\mathrm{DH} .{ }^{18}$ The potential strategy for management of $\mathrm{DH}$ is to effectively occlude the dentine tubules. The purpose of this study was to synthesized and evaluate the effectiveness of a ball-milled synthesized EB@ $@ \mathrm{TiO}_{2}$ to occlude open dentine tubules. As advocated by several authors, ${ }^{19,20,21}$ bovine teeth were used in this study as a substitute for human teeth in the in vitro experiment. Interestingly, it is worth mentioning that the radicular dentine morphology of human and bovine primary teeth and root are similar in terms of the diameter of the dentine tubules. ${ }^{22}$ 

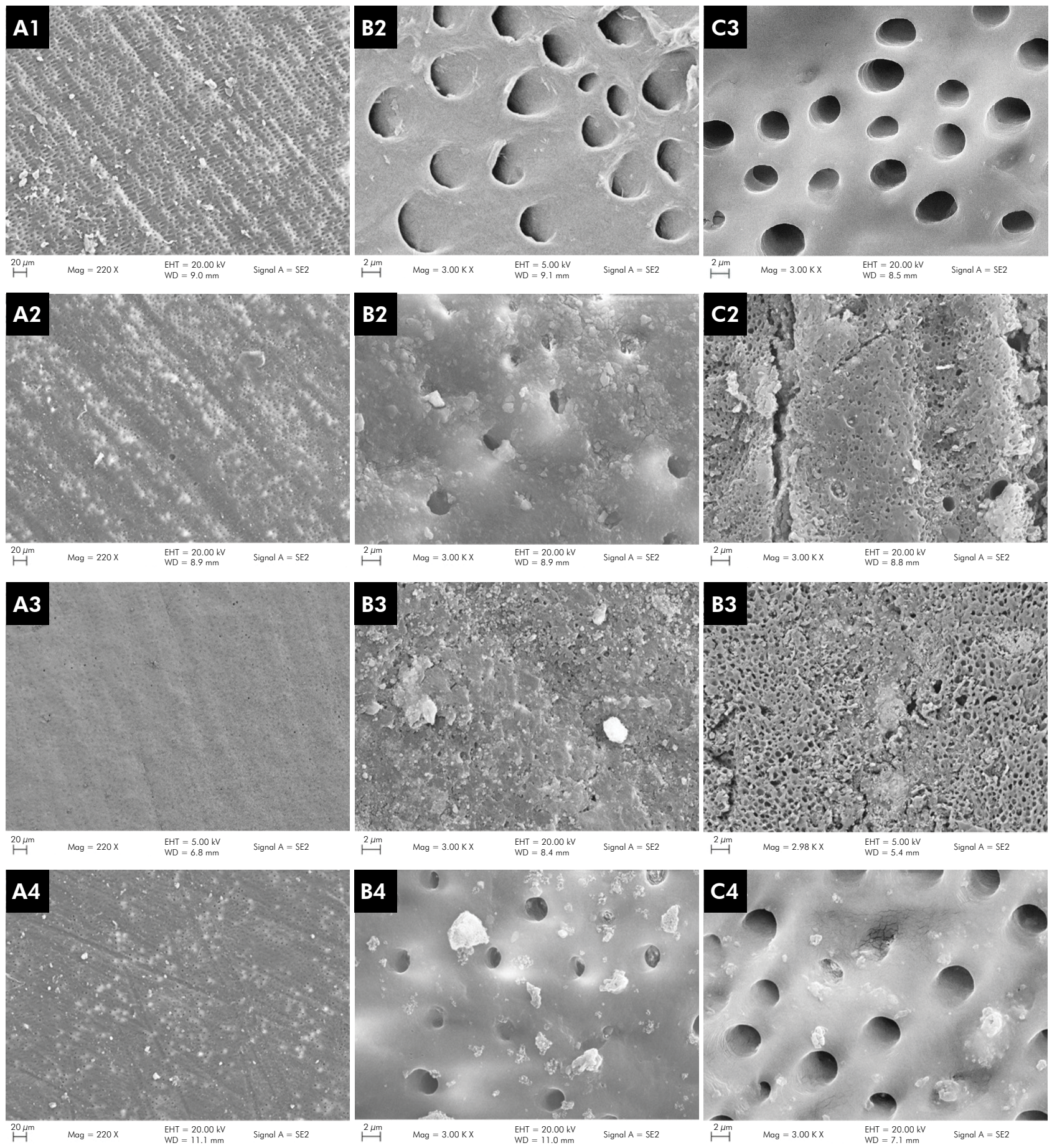

Figure 4. Representative SEM micrograph for dentine surface after treatment with different groups for 30min ( $A, x 220 ; B \times 3000$; Cx3000 Original magnification). (A1-B1) No treatment group; (A2-B2) eggshell powder treated group (A3-B3) EB@TiO 2 treated group; (A4-B4) Sensodyne treated group. (Agitated for 3hours). (C2) eggshell powder groups (C3) EB@ $\mathrm{TiO}_{2}$ treated group; (C4) Sensodyne groups. (post-exposure to 2 wt. \% citric acid solution for $5 \mathrm{~min}$ ).

Moreover, unlike human teeth, the bovine teeth with the more uniform composition are easy to obtain in large quantities with a relatively large flat surface and free of caries lesions and other defects. ${ }^{21}$ SEM was used to analyze the surface of the dentine pre-and post- treatment in $2 \mathrm{wt}$. \% citric 
acid. The stated hypothesis was accepted base on the study finding, as the exposed dentine tubules treated with $\mathrm{EB} @ \mathrm{TiO}_{2}$ demonstrate outstanding occlusion as well as acid resistant characteristics.

Overall, the occlusion of the dentine tubules observed in the samples treated with $\mathrm{EB} @ \mathrm{TiO}_{2}$, eggshell powder, and Sensodyne were significantly different $(p<0.001)$. Given the statistical difference between the eggshell powder and $\mathrm{EB} @ \mathrm{TiO}_{2}(\mathrm{p}<0.008)$, the observed differences could be attributed to the particle sizes of $\mathrm{EB} @ \mathrm{TiO}_{2}(\leq 13 \mathrm{~nm})$ and Eggshell powder $(\leq 25 \mu \mathrm{m})$. As reported by Nakashima et al., ${ }^{9}$ nano-sized calcium carbonate containing materials can potentially remineralize damaged teeth due to their unique properties which facilitate the attachment on the oral surface. Owing to this attachment, calcium ions are released into the oral fluid that occludes dentinal tubules.

Moreover, the occluding abilities of Sensodyne toothpaste were found to be significantly lower than both eggshell powder $(p<0.003)$ and EB@ $\mathrm{TiO}_{2}$ $(\mathrm{p}<0.001)$, respectively. The highest $(83.2 \pm 12.4)$ occlusion per area were observed in the samples treated with $\mathrm{EB} @ \mathrm{TiO}_{2}$ while the lowest $(25 \pm 8.04)$ was measured in the group treated with Sensodyne toothpaste. These differences may reflect on the composition and design of the toothpaste. According to Schiff et al., ${ }^{23}$ desensitizing toothpastes such as Sensodyne Colgate Sensitivity toothpaste are originally designed to deliver potassium ions that acts as a nerve depolarizing agents in the treatment of DH. Nevertheless, the mean number of occluded dentinal tubules measured in the Sensodyne treated group showed that the toothpaste could still potentially occlude dentinal tubules. Consistent with the early report of Pashley et al., ${ }^{24}$ the observed occlusion of some tubules in the samples treated with Sensodyne may be attributed to the silica composition in the toothpaste. This strongly supports the work of Wang et al. ${ }^{25}$ that toothpastes containing abrasive materials such as calcium carbonate and silica had the ability to form a new smear layer on the surface of the dentine; thereby occluding the dentinal.

Furthermore, the acid resistant characteristics of the treated samples were evaluated post-treatment using 2 wt.\% citric acid. Notably, the results visibly showed that acid resistant characteristics of EB@ $\mathrm{TiO}_{2}$ (Figure 4 C2) were superior to that of eggshell powder (Figure 4 C3) and Sensodyne toothpaste

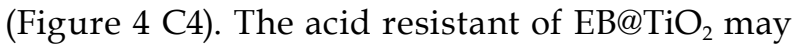
have been influenced by the deposition of $\mathrm{TiO}_{2}$ on the calcite (eggshell) surface (Figure 1). This is in agreement with the report of Tao et al. ${ }^{15}$ that titanium dioxide can improve the acid resistant properties of calcium carbonates. On the contrary, for Sensodyne toothpaste, Arnold et al..$^{10}$ reported that although certain toothpaste like Sensodyne may support dentinal occlusion; such occlusion are superficial and are dissolved with acids.

In reviewing literature related to the present study, the occlusion abilities and acid resistant characteristics of Nano/micro fluorhyhydroxyapatite crystals, ${ }^{26}$ nanohydroxyapatite/mesoporous ${ }^{11}$ silica composite and zinc oxide hydroxyapatite paste ${ }^{27}$ have shown promising results in the treatment of DH. Unlike the aforementioned materials, EB@ $\mathrm{TiO}_{2}$ bio composite had the advantage of being readily available since the bulk of the material is made from waste eggshell.

From an environmental sustainability and management perspective, and as argued by Onwubu et al., ${ }^{17}$ using eggshell waste material to treat $\mathrm{DH}$ will strengthen the economic benefits associated with using natural waste material, which is high on the global agenda for a greener environment. This argument is supported by Yazıcıŏ̆lu and Ulukap ${ }^{28}$ who pointed out that a low cost, affordable, feasible, and sustainable products need to be developed to repair and improved quality of life for patients who do not have to suffer toothache because of sensitivity. This suggests that $\mathrm{EB} @ \mathrm{TiO}_{2}$ has the potential to be used as an oral care product in the management of DH. Importantly, the cytotoxicity result (Figure 3), suggests that $\mathrm{EB} @ \mathrm{TiO}_{2}$ appeared to have little effect on the NIH 3T3 cell line. Further vivo research is, however, needed to fully and comprehensive characterize the cytotoxicity as well as the occluding potential of $\mathrm{EB} @ \mathrm{TiO}_{2}$ bio composite. This is an uncharted area of research worth exploring. 
Additionally, and despite the above outstanding occluding capabilities of $\mathrm{EB} @ \mathrm{TiO}_{2}$, some limitation was noticed in the present study. The agitation procedure cannot be used to predict the rate and the number of days in an oral condition required to completely occlude the tubules. Hence future studies are planned to evaluate the occluding abilities of the composite using the brushing procedure stored in the presence or absence of saliva. These studies will help establish the $\mathrm{EB} @ \mathrm{TiO}_{2}$ composite as an effective material to manage $\mathrm{DH}$.

\section{Conclusion}

In conclusion, this study confirmed that modified $\mathrm{EB} @ \mathrm{TiO}_{2}$ composite could effectively occlude dentine tubules. It was also demonstrated that the occlusion had depth and highly effective in acidic environment.

\section{Acknowledgment}

The authors acknowledged the financial support from the National Research Foundation of South Africa (No. 104824).

\section{References}

1. Canadian Advisory Board on Dentin Hypersensitivity. Consensus-based recommendations for the diagnosis and management of dentin hypersensitivity. J Can Dent Assoc. 2003 Apr;69(4):221-6.

2. Saeki K, Marshall GW, Gansky SA, Parkinson CR, Marshall SJ. Strontium effects on root dentin tubule occlusion and nanomechanical properties. Dent Mater. 2016 Feb;32(2):240-51. https://doi.org/10.1016/i.dental.2015.11.020

3. Schiff T, Delgado E, Zhang Y, Cummins D, DeVizio W, Mateo L. Clinical evaluation of the efficacy of an in-office desensitizing paste containing $8 \%$ arginine and calcium carbonate in providing instant and lasting relief of dentin hypersensitivity. Am J Dent. 2009 Mar;22 Spec No. A:8-15A.

4. Yang ZY, Wang F, Lu K, Li YH, Zhou Z. Arginine-containing desensitizing toothpaste for the treatment of dentin hypersensitivity: a metaanalysis. Clin Cosmet Investig Dent. 2016 Jan;8:1-14. https://doi.org/10.2147/CCIDE.S95660

5. Cunha-Cruz J, Stout JR, Heaton LJ, Wataha JC; Northwest PRECEDENT. Dentin hypersensitivity and oxalates: a systematic review. J Dent Res. 2011 Mar;90(3):304-10. https://doi.org/10.1177/0022034510389179

6. Pandit N, Gupta R, Bansal A. Comparative evaluation of two commercially available desensitizing agents for the treatment of dentinal hypersensitivity. Indian J Dent Res. 2012 Nov-Dec;23(6):778-83. https://doi.org/10.4103/0970-9290.111259

7. Babu KLG, Subramaniam P, Teleti S. Remineralization potential of varnish containing casein phosphopeptides-amorphous calcium phosphate with fluoride and varnish containing only fluoride: A comparative study. Saudi J Oral Sci. 2018;5(1):35. https://doi. org/10.4103/sjos.SJOralSci_44_17

8. Zalite V, Locs J. Characterization and preparation of calcium phosphate model toothpaste for tooth enamel remineralization. Key Eng Mater. 2017;721:213-8. https://doi.org/10.4028/www.scientific.net/KEM.721.213

9. Nakashima S, Yoshie M, Sano H, Bahar A. Effect of a test dentifrice containing nano-sized calcium carbonate on remineralization of enamel lesions in vitro. J Oral Sci. 2009 Mar;51(1):69-77. https://doi.org/10.2334/josnusd.51.69

10. Arnold WH, Prange M, Naumova EA. Effectiveness of various toothpastes on dentine tubule occlusion. J Dent. 2015 Apr;43(4):440-9. https://doi.org/10.1016/i.jdent.2015.01.014

11. Yu J, Yang H, Li K, Lei J, Zhou L, Huang C. A novel application of nanohydroxyapatite/mesoporous silica biocomposite on treating dentin hypersensitivity: an in vitro study. J Dent. 2016 Jul;50:21-9. https://doi.org/10.1016/i.jdent.2016.04.005

12. Macri DV. Implementing a minimally invasive approach. Dimens Dent Hyg. 2016 Mar;14(3):32-7.

13. Haghgoo R, Mehran M, Ahmadvand M, Ahmadvand MJ. Remineralization effect of eggshell versus nano-hydroxyapatite on caries-like lesions in permanent teeth (in vitro). J Int Oral Health. 2016;8(4):435-9.

14. Cutler ET, inventor; Squigle Inc, assignee. Prevention and treatment of oral diseases. United States patent US8658139 B1. Feb 25, 2014.

15. Tao H, He Y, Zhao X. Preparation and characterization of calcium carbonate-titanium dioxide core-shell (CaCO3@ TiO2) nanoparticles and application in the papermaking industry. Powder Technol. 2015;283:308-14. https://doi.org/10.1016/i.powtec.2015.05.039

16. Lin H, Dong Y, Jiang L. Preparation of calcium carbonate particles coated with titanium dioxide. International J Min Met Mater. 2009;16(5):592-7. https://doi.org/10.1016/S1674-4799(09)60102-3

17. Onwubu SC, Vahed A, Singh S, Kanny KM. Physicochemical characterization of a dental eggshell powder abrasive material. J Appl Biomater Funct Mater. 2017 Nov;15(4):e341-6. https://doi.org/10.5301/jabfm.5000361 
A novel application of nano eggshell/titanium dioxide composite on occluding dentine tubules: an in vitro study

18. Colombo M, Mirando M, Rattalino D, Beltrami R, Chiesa M, Poggio C. Remineralizing effect of a zinc-hydroxyapatite toothpaste on enamel erosion caused by soft drinks: ultrastructural analysis. J Clin Exp Dent. 2017 Jul;9(7):e861-8. https://doi.org/10.4317/jced.53790

19. Fonseca RB, Haiter-Neto F, Fernandes-Neto AJ, Barbosa GA, Soares CJ. Radiodensity of enamel and dentin of human, bovine and swine teeth. Arch Oral Biol. 2004 Nov;49(11):919-22. https://doi.org/10.1016/j.archoralbio.2004.05.006

20. Tanaka JL, Medici Filho E, Salgado JA, Salgado MA, Moraes LC, Moraes ME, et al. Comparative analysis of human and bovine teeth: radiographic density. Braz Oral Res. 2008 Oct-Dec;22(4):346-51. https://doi.org/10.1590/S1806-83242008000400011

21. Yassen GH, Platt JA, Hara AT. Bovine teeth as substitute for human teeth in dental research: a review of literature. J Oral Sci. 2011 Sep;53(3):273-82. https://doi.org/10.2334/josnusd.53.273

22. Costa BM, Iwamoto AS, Puppin-Rontani RM, Pascon FM. Comparative analysis of root dentin morphology and structure of human versus bovine primary teeth. Microsc Microanal. 2015 Jun;21(3):689-94. https://doi.org/10.1017/S1431927615000434

23. Schiff T, Bonta Y, Proskin HM, DeVizio W, Petrone M, Volpe AR. Desensitizing efficacy of a new dentifrice containing $5.0 \%$ potassium nitrate and 0.454\% stannous fluoride. Am J Dent. 2000 Jun;13(3):111-5.

24. Pashley DH, O'Meara JA, Kepler EE, Galloway SE, Thompson SM, Stewart FP. Dentin permeability: effects of desensitizing dentifrices in vitro. J Periodontol. 1984 Sep;55(9):522-5. https://doi.org/10.1902/jop.1984.55.9.522

25. Wang Z, Sa Y, Sauro S, Chen H, Xing W, Ma X, et al. Effect of desensitising toothpastes on dentinal tubule occlusion: a dentine permeability measurement and SEM in vitro study. J Dent. 2010 May;38(5):400-10. https://doi.org/10.1016/i.jdent.2010.01.007

26. Taha ST, Han H, Chang SR, Sovadinova I, Kuroda K, Langford RM, et al. Nano/micro fluorhydroxyapatite crystal pastes in the treatment of dentin hypersensitivity: an in vitro study. Clin Oral Investig. 2015 Nov;19(8):1921-30. https://doi.org/10.1007/s00784-015-1427-2

27. Poggio C, Gulino C, Mirando M, Colombo M, Pietrocola G. Protective effect of zinc-hydroxyapatite toothpastes on enamel erosion: an in vitro study. J Clin Exp Dent. 2017 Jan;9(1):e118-22. https://doi.org/10.4317/iced.53068

28. Yazıcıoğlu $\mathrm{O}$, Ulukapı $\mathrm{H}$. The investigation of non-invasive techniques for treating early approximal carious lesions: an in vivo study. Int Dent J. 2014 Feb;64(1):1-11. https://doi.org/10.1111/idj.12056 